\title{
Selective Photothermal Therapy for Mixed Cancer Cells Using Aptamer-Conjugated Nanorods
}

\author{
Yu-Fen Huang, ${ }^{\dagger}$ Kwame Sefah, ${ }^{\dagger}$ Suwussa Bamrungsap,${ }^{\dagger}$ Huan-Tsung Chang, ${ }^{\ddagger}$ and \\ Weihong Tan*, ${ }^{\dagger}$ \\ Center for Research at the Bio/Nano Interface, Department of Chemistry and Department of Physiology \\ and Functional Genomics, Shands Cancer Center, Genetics Institute, and McKnight Brain Institute, \\ University of Florida, Gainesville, Florida 32611-7200, and Department of Chemistry, National Taiwan
} University, Taipei, Taiwan

Received June 23, 2008

\begin{abstract}
Safe and effective photothermal therapy depends on efficient delivery of heat for killing cells and molecular specificity for targeting cells. To address these requirements, we have designed an aptamer-based nanostructure which combines the high absorption efficiency of $\mathrm{Au}-\mathrm{Ag}$ nanorods with the target specificity of molecular aptamers, a combination resulting in the development of an efficient and selective therapeutic agent for targeted cancer cell photothermal destruction. Most nanomaterials, such as gold nanoshells or nanorods (NRs), require a relatively high power of laser irradiation $\left(1 \times 10^{5}-1 \times 10^{10} \mathrm{~W} / \mathrm{m}^{2}\right)$. In contrast, the high absorption characteristic of our $\mathrm{Au}-\mathrm{Ag}$ NRs requires only $8.5 \times 10^{4} \mathrm{~W} / \mathrm{m}^{2}$ laser exposure to induce $93( \pm 11) \%$ cell death of NR-aptamer-labeled cells. Aptamers, the second component of the nanostructure, are generated from a cell-SELEX (systematic evolution of ligands by exponential enrichment) process and can be easily selected for specific recognition of individual tumor cell types without prior knowledge of the biomarkers for the cell. When tested with both cell suspensions and artificial solid tumor samples, these aptamer conjugates were shown to have excellent hyperthermia efficiency and selectivity. Under a specific laser intensity and duration of laser exposure, about $50( \pm 1) \%$ of target (CEM) cells were severely damaged, while more than $87( \pm 1) \%$ of control (NB-4) cells remained intact in a suspension cell mixture. These results indicate that the $\mathrm{Au}-\mathrm{Ag}$ nanorod combination offers selective and efficient photothermal killing of targeted tumor cells, thus satisfying the two key challenges noted above. Consequently, for future in vivo application, it is fully anticipated that the tumor tissue will be selectively destroyed at laser energies which will not harm the surrounding normal tissue.
\end{abstract}

\section{Introduction}

Currently, hyperthermia is considered a relatively noninvasive and benign alternative for cancer treatment. This treatment modality exposes biological tissues to higher than normal temperature to promote the destruction of abnormal cells. As such, it can be classified into different regimens based on the elevated temperature ranges. ${ }^{1}$ For low and moderate temperature hyperthermia $\left(39-45^{\circ} \mathrm{C}\right)$, cancer cells are easily sensitized to cytotoxic agents as a result of increasing membrane permeability and decreasing hydrostatic pressure. Thermal ablation, or high temperature thermal therapy $\left(>50^{\circ} \mathrm{C}\right)$, applies heat to directly modify or destroy tissue. This type of therapy can induce the denaturation of proteins or the disruption of organized biomolecular assemblies in the nucleus and cytoskeleton.

Many different types of energy sources, including radiofrequency, ${ }^{2,3}$ microwave, ${ }^{4}$ ultrasound ${ }^{5}$ and laser irradiation, ${ }^{6}$ have been used for the external delivery of thermal energy. Photothermal therapy, which has recently attracted much attention,

* To whom correspondence should be addressed. E-mail: tan@ chem.ufl.edu. Telephone and fax: $(+1)$ 352-846-2410.

+ University of Florida

* National Taiwan University.

(1) Stauffer, P. R. Int. J. Hyperthermia 2005, 21, 731-744.

(2) Gazelle, G. S.; Goldberg, S. N.; Solbiati, L.; Livraghi, T. Radiology 2000 , 217, 633-646.

(3) Mirza, A. N.; Fornage, B. D.; Sneige, N.; Kuerer, H. M.; Newman, L. A.; Ames, F. C.; Singletary, S. E. Cancer J. 2001, 7, 95-102.

(4) Seki, T.; Wakabayashi, M.; Nakagawa, T.; Imamura, M.; Tamai, T.; Nishimura, A.; Yamashiki, N.; Okamura, A.; Inoue, K. Cancer 1999, 85, 16941702 .

(5) Jolesz, F. A.; Hynynen, K. Cancer J. 2002, 8, S100-S112.

(6) Vogl, T. J.; Mack, M. G.; Muller, P. K.; Straub, R.; Engelmann, K.; Eichler, K. Eur. Radiol. 1999, 9, 1479-1487. uses lasers for the thermal treatment of tumors and has the intensity required to achieve deep-tissue penetration with high spatial precision, especially at near-infrared (NIR) frequencies. ${ }^{7}$ However, to achieve optimal effectiveness, this method requires both photoabsorbers and photothermal convectors to allow increased heat production within a localized region at lower incident energies. This demands the development of metal nanoshells ${ }^{8,9}$ and anisotropic gold nanoparticles $(\mathrm{Au} \mathrm{NPs})^{10,11}$ which can support plasmon resonances with remarkably high absorption cross sections at NIR frequencies. Thus far, the efficacy of this strategy has been demonstrated by successful tumor remission in mice. In this case, nanoshell-mediated hyperthermia by NIR irradiation was applied for several minutes at power densities of only $4 \mathrm{~W} / \mathrm{cm}^{2}{ }^{12}$

Gold nanorods (Au NRs) are especially attractive candidates for exploitation in photothermal therapy because they can be readily synthesized with various aspect ratios, which enable selective absorption in the NIR region. They also support a higher absorption cross section at NIR frequencies per unit volume

(7) Chen, W. R.; Adams, R. L.; Carubelli, R.; Nordquist, R. E. Cancer Lett. 1997, 115, 25-30.

(8) Hirsch, L. R.; Stafford, R. J.; Bankson, J. A.; Sershen, S. R.; Rivera, B.; Price, R. E.; Hazle, J. D.; Halas, N. J.; West, J. L. Proc. Natl. Acad. Sci. U.S.A. 2003, 100, 13549-13554.

(9) Gobin, A. M.; Lee, M. H.; Halas, N. J.; James, W. D.; Drezek, R. A.; West, J. L. Nano Lett. 2007, 7, 1929-1934.

(10) Chen, J. Y.; Wang, D. L.; Xi, J. F.; Au, L.; Siekkinen, A.; Warsen, A.; Li, Z. Y.; Zhang, H.; Xia, Y. N.; Li, X. D. Nano Lett. 2007, 7, 1318-1322.

(11) Huang, X. H.; El-Sayed, I. H.; Qian, W.; El-Sayed, M. A. J. Am. Chem. Soc. 2006, 128, 2115-2120.

(12) O’Neal, D. P.; Hirsch, L. R.; Halas, N. J.; Payne, J. D.; West, J. L. Cancer Lett. 2004, 209, 171-176. 
than most other types of NPs, including nanoshells. ${ }^{13-15}$ In addition to targeting tumor cells, Au NRs have recently been used as a photothermal modality to destroy different types of target cells. ${ }^{11,13,14}$ Core-shell and alloyed multimetallic $\mathrm{Au}-$ based nanomaterials having optical properties that differ from those of Au NRs are also interesting materials. ${ }^{16-18}$ Particularly, $\mathrm{Au}-\mathrm{Ag}$ NRs possess sharper and stronger longitudinal surface plasmon resonance (SPR) bands than those for spherical Au NPs or Au NRs. Hence, $\mathrm{Au}-\mathrm{Ag}$ NRs appear to be a new class of photothermal convectors in photothermal therapy.

In addition to photothermal conversion, specificity of targeting is another key problem. By its range of thermal application, this is difficult to achieve using hyperthermia. Ideally, specific targeting should produce only minimal heat in the surrounding tissue. To accomplish this, small particles in the $60-400 \mathrm{~nm}$ size range can be accumulated in tumors by means of a passive mechanism known as the "enhance permeability and retention" (EPR) effect. ${ }^{19,20}$ In the alternative, active targeting is an equally effective tool whereby molecular probes are applied for specific cell recognition. ${ }^{21-23}$ Most recently, a novel class of ligands, termed aptamers, has been isolated and identified for specific tumor cell recognition. Aptamers are RNA or DNA molecules that fold by intramolecular interaction into unique three-dimensional conformations for target recognition. They can be selected by a process known as SELEX (systematic evolution of ligands by exponential enrichment) ${ }^{24,25}$ from a pool of DNA or RNA by repetitive binding of the target molecules. Aptamers possess numerous advantageous characteristics, including small size, lack of immunogenicity, and ease of synthesis, all of which rival those of other molecular probes, including antibodies. ${ }^{26,27}$ While most aptamers reported so far have been selected for single targets, such as proteins, drugs, or amino acids, whole living cells have also been used as targets for the selection of a panel of aptamers (cell-SELEX) for specific cell recognition. ${ }^{28-30}$ This advancement has paved the way for recognition of the unique molecular signatures of cancer cells in early diagnosis and targeted therapy.

In this work, we will demonstrate the use of aptamer-conjugated NRs for targeted photothermal therapy. Since these $\mathrm{Au}-$ Ag NRs show excellent absorption in the NIR range, they are an efficient photothermal convector by which to generate localized

(13) Huff, T. B.; Tong, L.; Zhao, Y.; Hansen, M. N.; Cheng, J. X.; Wei, A. Nanomedicine 2007, 2, 125-132.

(14) Pissuwan, D.; Valenzuela, S. M.; Miller, C. M.; Cortie, M. B. Nano Lett. 2007, 7, 3808-3812.

(15) Jain, P. K.; Lee, K. S.; El-Sayed, I. H.; El-Sayed, M. A. J. Phys. Chem. B 2006, 110, 7238-7248. 7873 .

(16) Ah, C. S.; Hong, S. D.; Jang, D. J. J. Phys. Chem. B 2001, 105, 7871-

(17) Liu, M.; Guyot-Sionnest, P. J. Phys. Chem. B 2004, 108, 5882-5888.

(18) Huang, Y.-F.; Huang, K.-M.; Chang, H.-T. J. Colloid Interface Sci. 2006,

$301,145-154$

(19) Maeda, H. Adv. Enzyme Regul. 2001, 41, 189-207.

(20) Maeda, H.; Fang, J.; Inutsuka, T.; Kitamoto, Y. Int. Immunopharmacol. 2003, 3, 319-328.

(21) Huang, X. H.; Jain, P. K.; El-Sayed, I. H.; El-Sayed, M. A. Photochem. Photobiol. 2006, 82, 412-417.

(22) Loo, C.; Lowery, A.; Halas, N.; West, J.; Drezek, R. Nano Lett. 2005, 5, 709-711.

(23) Pissuwan, D.; Cortie, C. H.; Valenzuela, S. M.; Cortie, M. B. Gold Bull. 2007, 40, 121-129.

(24) Green, R.; Ellington, A. D.; Szostak, J. W. Nature 1990, 347, 406-408.

(25) Tuerk, C.; Gold, L. Science 1990, 249, 505-510.

(26) Brody, E. N.; Gold, L. J. Biotechnol. 2000, 74, 5-13.

(27) Jayasena, S. D. Clin. Chem. 1999, 45, 1628-1650.

(28) Daniels, D. A.; Chen, H.; Hicke, B. J.; Swiderek, K. M.; Gold, L. Proc. Natl. Acad. Sci. U.S.A. 2003, 100, 15416-15421.

(29) Shangguan, D.; Li, Y.; Tang, Z.; Cao, Z. C.; Chen, H. W.; Mallikaratchy, P.; Sefah, K.; Yang, C. J.; Tan, W. Proc. Natl. Acad. Sci. U.S.A. 2006, 103 $11838-11843$.

(30) Tang, Z. W.; Shangguan, D.; Wang, K. M.; Shi, H.; Sefah, K.; Mallikratchy, P.; Chen, H. W.; Li, Y.; Tan, W. H. Anal. Chem. 2007, 79, 4900-4907. heating. Equally important, through covalent linkages of aptamers on the nanorod surface, we can also enable specific cell targeting as well as selective photothermal destruction of cancer cells in vitro.

\section{Experimental Section}

Chemicals. Cetyltrimetylammonium bromide (CTAB), sodium tetrachloroaurate(III) dihydrate $\left(\mathrm{NaAuCl}_{4} \cdot 2 \mathrm{H}_{2} \mathrm{O}, 99 \%\right)$, sodium borohydride $\left(\mathrm{NaBH}_{4}, 98 \%\right)$, bovine serum albumin (BSA), and tris (2carboxyethyl)phosphine (TCEP) were obtained from Sigma-Aldrich (St. Louis, MO). Ascorbic acid, glycine, Tris, and silver nitrate $\left(\mathrm{AgNO}_{3}, 99 \%\right)$ were obtained from Fisher Scientific (Houston, TX). Deoxyribonucleotides, spacer phosphoramidite 18 , and $5^{\prime}$-thiol modifiers were purchased from Glen Research (Sterling, VA). Antibody against CD5 was purchased from BD Biosciences. The $\mathrm{pH}$ value of the solution containing glycine $(0.5 \mathrm{M})$ was adjusted with $2.0 \mathrm{M} \mathrm{NaOH}$ to 8.0 . Deionized water $(18.2 \mathrm{M} \Omega \cdot \mathrm{cm})$ was used to prepare all of the aqueous solutions.

Synthesis of Au NR Seeds. Au NR seeds were prepared using a slightly modified seeding method described previously. ${ }^{37} \mathrm{CTAB}$ aqueous solution $(0.2 \mathrm{M}, 5.0 \mathrm{~mL})$ was mixed with $0.5 \mathrm{mM} \mathrm{NaAuCl}_{4}$ $(5.0 \mathrm{~mL})$. Ice-cold $0.01 \mathrm{M} \mathrm{NaBH}_{4}(0.6 \mathrm{~mL})$ was added to this solution under sonication. Reaction of this mixture for $3 \mathrm{~min}$ resulted in the formation of a brownish-yellow seed solution. In the growth solution, CTAB $(0.2 \mathrm{M}, 50.0 \mathrm{~mL})$ was mixed with $1.0 \mathrm{mM} \mathrm{NaAuCl}_{4}(50.0$ $\mathrm{mL})$ and $\mathrm{AgNO}_{3}(0.1 \mathrm{M}, 0.1 \mathrm{~mL})$. After gentle mixing of the solution, $78.8 \mathrm{mM}$ ascorbic acid $(0.7 \mathrm{~mL})$ was added as a mild reducing agent. The color of the growth solution changed rapidly from darkyellow to colorless, indicating the formation of $\mathrm{AuCl}_{2}{ }^{-}$ions. Finally, a portion of the seed solution $(0.12 \mathrm{~mL})$ was added to the growth solution. The solution gradually changed color to dark-pink over a period of $30 \mathrm{~min}$, indicating the formation of Au NR seeds. The as-prepared Au NR seed solutions were used directly to prepare the $\mathrm{Au}-\mathrm{Ag}$ NRs without any further purification.

Synthesis of $\mathbf{A u}-\mathbf{A g ~ N R s}$. Aliquots $(50.0 \mathrm{~mL})$ of the as-prepared $\mathrm{Au}$ NR seed solutions (original $\mathrm{pH} \sim 3.0$ ) were mixed with $0.2 \mathrm{M}$ glycine solutions $(50.0 \mathrm{~mL} ; \mathrm{pH} 8.0$ ); note that the Au NR seed solutions still contained $\mathrm{Ag}$ and $\mathrm{Au}$ ions as well as ascorbic acid. ${ }^{43}$ These mixtures were incubated without stirring at room temperature overnight to form $\mathrm{Au}-\mathrm{Ag}$ NRs. The sizes of the as-prepared $\mathrm{CTAB}-\mathrm{Au}-\mathrm{Ag} \mathrm{NRs}$ were verified through transmission electron microscopy (TEM) analysis (Hitachi H7100, Tokyo, Japan); these nanocomposites appeared to be monodisperse, with an average length of $53 \pm 7 \mathrm{~nm}$ and width of $14 \pm 2 \mathrm{~nm}$. A Cintra 10e double-beam UV-vis spectrophotometer (GBC, Victoria, Australia) was used to measure the absorptions of NR solutions. The transverse and longitudinal absorption bands of the $\mathrm{CTAB}-\mathrm{Au}-\mathrm{Ag}$ NRs were centered at wavelengths of 513 and $800 \mathrm{~nm}$, respectively. The formation of $\mathrm{Au}-\mathrm{Ag}$ NRs was further confirmed by energy-dispersive $\mathrm{X}$-ray, X-ray photoelectron spectroscopy, and inductively coupled plasma mass spectrometry (ICP-MS) measurements. ${ }^{18}$

Synthesis of DNA Aptamer. The following aptamer has been selected for the CCRF-CEM: sgc8c, 5'-ATC TAA CTG CTG CGC CGC CGG GAA AAT ACT GTA CGG TTA GA-3'. A high-pressure liquid chromatography (HPLC) purified library containing a randomized sequence of 41 nucleotides was used as a control. Both of the aptamers were coupled with $5^{\prime}$-thiol modifier containing 12 extra (ethylene oxide) units. An ABI 3400 DNA/RNA synthesizer (Applied Biosystems, Foster City, CA) was used for the synthesis of all DNA sequences. A ProStar HPLC instrument (Varian, Walnut Creek, CA) with a C18 column (Econosil, $5 \mathrm{u}, 250 \times 4.6 \mathrm{~mm}$ ) from Alltech (Deerfield, IL) was used to purify all fabricated DNA. A Cary Bio-300 UV spectrometer (Varian, Walnut Creek, CA) was used to measure absorbances to quantify the manufactured sequences. All oligonucleotides were synthesized by solid-state phosphoramidite chemistry at a $1 \mu \mathrm{mol}$ scale. The completed sequences were then deprotected in AMA (ammonium hydroxide/40\% aqueous methylamine 1:1) at $65^{\circ} \mathrm{C}$ for $20 \mathrm{~min}$ and further purified with reverse phase HPLC on a C-18 column. 


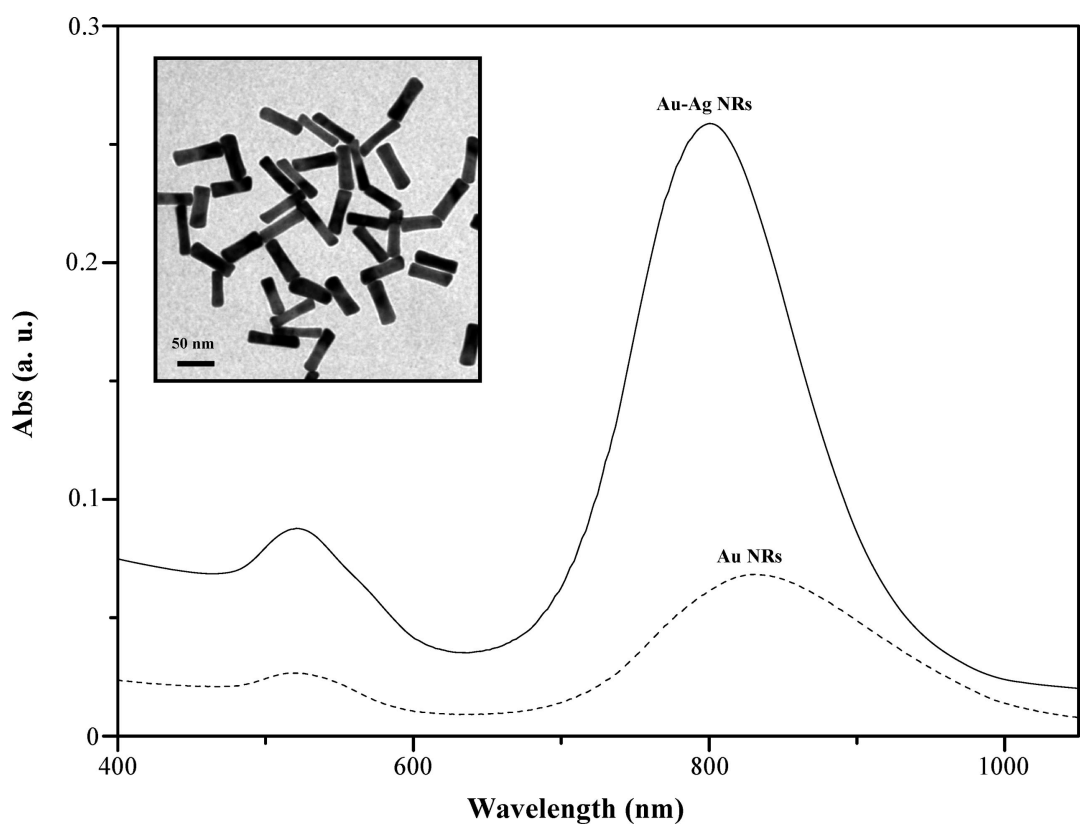

Figure 1. Absorption spectrum and TEM image of $\mathrm{Au}-\mathrm{Ag}$ NRs. The dimensions of these nanostructures are about $14 \pm 2 \mathrm{~nm}$ in width and $53 \pm$ $7 \mathrm{~nm}$ in length. They possess two resonance absorption bands at 513 and $800 \mathrm{~nm}$. The dotted curve in the absorption spectrum represents the original Au NR seeds.

Functionalization of $\mathbf{A u}-\mathbf{A g}$ NRs. Before DNA loading, the thiol functionality on the oligonucleotides was deprotected. The $5^{\prime}$-thiol aptamer $(0.1 \mathrm{mM})$ was deprotected by $0.1 \mathrm{mM}$ TCEP in 50 $\mathrm{mM}$ Tris- $\mathrm{HCl}(\mathrm{pH} 7.5)$ buffer for $1 \mathrm{~h}$ at room temperature. The as-prepared $\mathrm{Au}-\mathrm{Ag} \mathrm{NR}$ solutions $(100.0 \mathrm{~mL})$ were subjected to two wash-centrifugation cycles to remove excess CTAB before DNA conjugation. Centrifugation was conducted at $12000 \mathrm{rpm}$ for $10 \mathrm{~min}$, and deionized water $(100 \mathrm{~mL})$ was used for washing in each cycle. The final CTAB concentration of the purified NRs $(0.25 \mathrm{nM})$ was reduced to $50 \mu \mathrm{M}$. To stabilize and functionalize the $\mathrm{Au}-\mathrm{Ag}$ NRs, we coated them with BSA $(10 \mu \mathrm{M})$ and alkanethiol aptamer $(5 \mu \mathrm{M})$. The mixtures were then incubated for $12 \mathrm{~h}$ and purified by centrifugation at $12000 \mathrm{rpm}$ for $3 \mathrm{~min}$.

Cell Lines and Buffers. CCRF-CEM cells (CCL-119 T-cell, human acute lymphoblastic leukemia) and HeLa cells (CCL-2) were obtained from the American type Culture Association (ATCC). NB-4 cells (acute promyelocytic leukemia) were obtained from the Department of Pathology at the University of Florida. The cells were cultured in RPMI medium supplemented with $10 \%$ fetal bovine serum and $100 \mathrm{IU} / \mathrm{mL}$ penicillin-streptomycin. The cell density was determined using a hemocytometer, and this was performed prior to any experiments. After this, approximately $1 \times 10^{6}$ cells dispersed in buffer [ $4.5 \mathrm{~g} / \mathrm{L}$ glucose and $5 \mathrm{mM} \mathrm{MgCl}_{2}$ in Dulbecco's PBS with calcium chloride and magnesium chloride (Sigma)] were centrifuged at $970 \mathrm{rpm}$ for $3 \mathrm{~min}$ and redispersed in the same buffer for incubation. During all experiments, the cells were kept in an ice bath at $4{ }^{\circ} \mathrm{C}$.

NIR Photothermal Therapy. For the laser irradiation experiment, a CW diode laser (Thorlabs, Newton, NJ) at $808 \mathrm{~nm}$ was used. This wavelength is in the NIR region at which tissue has low absorption. It also overlaps efficiently with the longitudinal absorption band of the NRs. For suspension cells, the binding was preformed by incubating the mixture of $1 \times 10^{6}$ cells and apt-NRs $(0.25 \mathrm{nM})$ on ice for $2 \mathrm{~h}$. After that, the cells were washed twice by centrifugation with buffer of $0.6 \mathrm{~mL}$ and resuspended in a $40 \mu \mathrm{L}$ volume of buffer. A total of $10 \mu \mathrm{L}$ of cell suspension was put in a $3 \mathrm{~mm}$ well and illuminated by NIR light with variable power densities for $5 \mathrm{~min}$. Cells were then stained with $1 \mu \mathrm{g} / \mathrm{mL}$ propidium iodide (PI; Invitrogen, Carlsbad, CA) at room temperature for $20 \mathrm{~min}$ to test cell viability. Dead cells, which can accumulate the dye and show red fluorescence, were determined by using a FACScan cytometer (Becton Dickinson Immunocytometry Systems, San Jose, CA). The dead cells percentage was defined as the ratio of the number of red cells to total cells in flow cytometry. To determine adherent cells, the cells were cleaved by trypsin and replated onto a $10 \mathrm{~mm}$ glass coverslip in a Petri dish and allowed to grow for 1 day. The cell monolayer on the coverslip was then rinsed with buffer twice and immersed into the apt-NR solution on ice for $2 \mathrm{~h}$. After incubation, cells were rinsed with buffer to remove unbound particles and then exposed to the laser for $10 \mathrm{~min}$. After PI staining, the red fluorescence of dead cells was imaged under $10 \times$ magnification on a confocal laser scanning microscope (FluoView 500; Olympus, Center Valley, PA).

\section{Results and Discussion}

The $\mathrm{Au}-\mathrm{Ag}$ NRs were fabricated with a $14 \pm 2 \mathrm{~nm}$ width and a $53 \pm 7 \mathrm{~nm}$ length. This design results in strong longitudinal absorption in the NIR range which overlaps the region of minimum extinction of human tissues (Figure 1). ${ }^{31}$ Moreover, in comparison to $\mathrm{Au}$ NRs, $\mathrm{Au}-\mathrm{Ag}$ NRs possess higher molar absorptivity (dotted curve in Figure 1). ${ }^{11,32}$ In order to minimize aggregation and resistance to protein nonspecific binding in physiological environments, ${ }^{33}$ BSA was used to passivate the surface of the NRs through electrostatic physisorption interaction. After exposure to BSA, the positively charged surface of the NRs changed to a negatively charged surface. The incorporation with aptamers could then be preformed on NR surfaces through simple thiol linkages. ${ }^{34}$ Spectrophotometric analysis revealed only a $<10 \%$ reduction in the aptamer-NR conjugates' peak absorbance after suspension in saline, confirming successful retention of nanorod stability using BSA. Aptamer sgc8c (a strong aptamer with $K_{\mathrm{d}}$ values in the nanometer range) was selected for binding to the membrane protein of CCRF-CEM cells. ${ }^{29,35}$ By exposure to different aptamer concentrations and repetitive sedimentation to wash off unbound aptamers from NRs, the

(31) Shah, N.; Cerussi, A.; Eker, C.; Espinoza, J.; Butler, J.; Fishkin, J.; Hornung, R.; Tromberg, B. Proc. Natl. Acad. Sci. U.S.A. 2001, 98, 4420-4425.

(32) Huang, C. C.; Yang, Z.; Chang, H. T. Langmuir 2004, 20, 6089-6092.

(33) Takahashi, H.; Niidome, T.; Kawano, T.; Yamada, S.; Niidome, Y. J. Nanopart. Res. 2008, 10, 221-228.

(34) Love, J. C.; Estroff, L. A.; Kriebel, J. K.; Nuzzo, R. G.; Whitesides, G. M. Chem. Rev. 2005, 105, 1103-1170.

(35) Shangguan, D.; Tang, Z. W.; Mallikaratchy, P.; Xiao, Z. Y.; Tan, W. H. ChemBioChem 2007, 8, 603-606. 
(A)

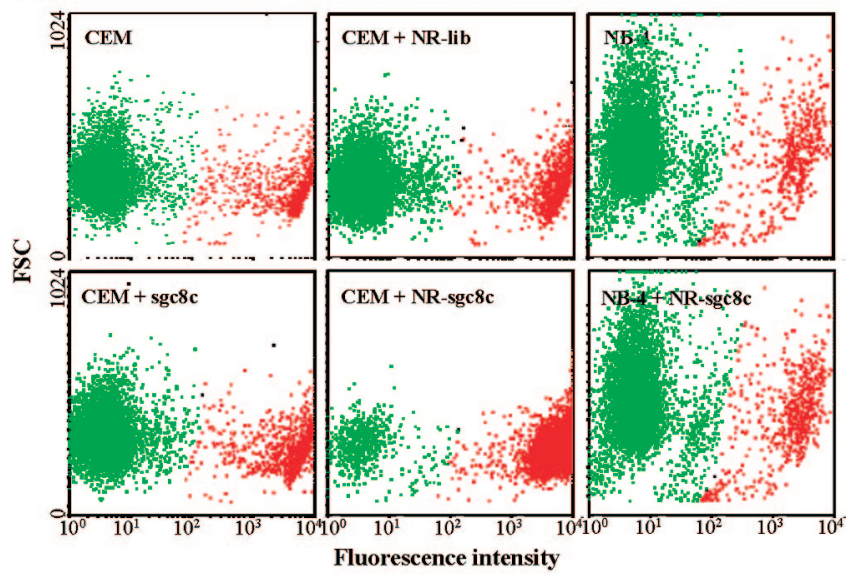

(B)

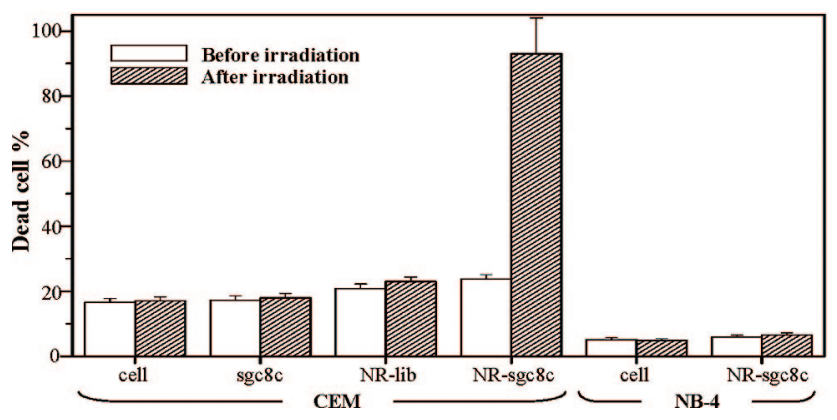

Figure 2. (A) Flow cytometric comparison between live and dead cell populations of CCRF-CEM cells (target cells) and NB-4 cells (control cells) without NRs and those labeled with sgc $8 \mathrm{c}(50 \mathrm{nM}), \mathrm{NR}-\mathrm{lib}(0.25$ $\mathrm{nM})$, and NR-sgc $8 \mathrm{c}(0.25 \mathrm{nM})$. A total of $10 \mu \mathrm{L}$ of the cell suspensions is irradiated with NIR light $(808 \mathrm{~nm})$ at $600 \mathrm{~mW}$ for $5 \mathrm{~min}$. Dead cells are then stained with PI dye, diluted in buffer, and determined by flow cytometry. (B) Bar chart demonstrating the dead cell percentages of CCRF-CEM cells (target cells) and NB-4 cells (control cells) in all experimental conditions before and after NIR irradiation.

conjugation efficiency of fluorescein-labeled aptamer to $\mathrm{Au}-\mathrm{Ag}$ NRs was determined. Our previous result demonstrated that approximately 80 aptamer molecules were bound on each NR. ${ }^{36}$

To demonstrate the specific binding of our NR-conjugated aptamers, the conjugates were added to the cell suspension, followed by flow cytometric analysis. After a $2 \mathrm{~h}$ incubation with NR-conjugated random DNA library (NR-lib) and NRconjugated aptamer sgc8c (NR-sgc8c), a noticeable change in the fluorescence signal between NR-lib- and NR-sgc8c-labeled CCRF-CEM cells indicates that the binding capability of the aptamer probes is maintained well after conjugation with NRs (Figure S1, Supporting Information). No significant change in fluorescence intensity was observed for NB-4 cells, a control cell line which does not bind with the ags8 aptamer, further confirming the specific recognition of the NR-aptamer conjugates for target cells. Similar results could also be monitored by confocal microscopy. After incubation with NR-conjugated sgc8c $(0.25$ $\mathrm{nM})$, CEM cells presented very bright fluorescence on their periphery, whereas no fluorescence was displayed when using NR-lib in the same concentration. In contrast, fluorescence from the nanoconjugates was not observed in either case for the control NB-4 cells. It was found that autofluorescence of NB-4 cells did result in some red spots in the confocal images. However, this observation correlated well with the higher background of NB-4 cells compared to that of CEM cells in flow cytometry. Finally,

(36) Huang, Y. F.; Chang, H. T.; Tan, W. Anal. Chem. 2008, 80, 567-572.
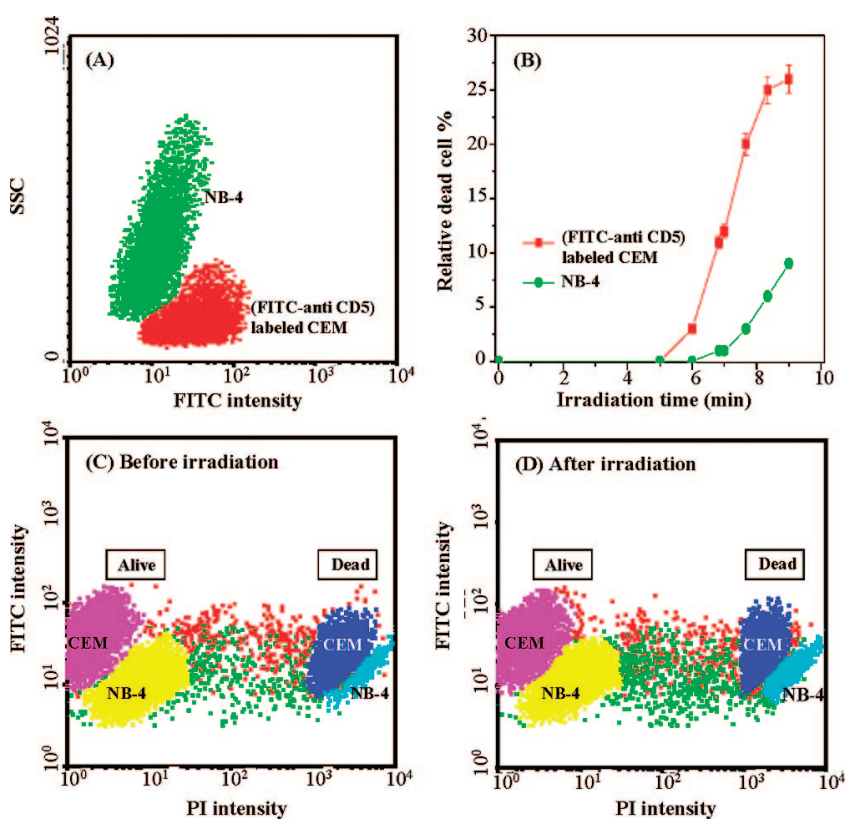

Figure 3. Comparison between the dead cell percentage of FITC-labeled anti-CD5 CEM cells (target cells) and NB-4 cells (control cells) in a cell mixture after NR-sgc $8 \mathrm{c}$ incubation $(0.25 \mathrm{nM})$. A total of $10 \mu \mathrm{L}$ of the cell suspensions is irradiated with NIR light $(808 \mathrm{~nm})$ at $600 \mathrm{~mW}$ for 0-9 min. Dead cells are then stained with PI dye, diluted in buffer, and determined by flow cytometry. (A) Red and green dots represent the cells of FITC-labeled anti-CD CEM cells and NB-4 cells, respectively. (B) Comparison of the relative dead cell percentage between FITClabeled anti-CD5 CEM cells and NB-4 cells as exposure time increases. Panels (C) and (D) show the dot plots of the cell population before and after irradiation, respectively, with NIR light $(808 \mathrm{~nm})$ at $600 \mathrm{~mW}$ for 9 min. The R1 (blue) and R2 (light blue) regions represent the dead cells of FITC-labeled anti-CD5 CEM cells and NB-4 cells, respectively.

it should be noted that molecular assembly of aptamers on NR surfaces has been shown to produce simultaneous multivalent interactions with the cell membrane receptors, leading to an affinity at least 26-fold higher than the intrinsic affinity of the original aptamer probes. ${ }^{36}$ This will significantly improve binding affinity with cancer cells.

The $\mathrm{Au}-\mathrm{Ag}$ NRs used in this experiment were synthesized by using CTAB as a soft template. ${ }^{37}$ To confirm the nontoxicity of bound CTAB surfactants to leukemia cells in the absence of plasmonic heating, the following steps were carried out. First, since unbound CTAB surfactants in solution have been reported to be cytotoxic, ${ }^{38}$ free CTAB of NR-aptamer conjugates was removed prior to each treatment. Second, without application of laser irradiation and after an incubation period of $2 \mathrm{~h}$, the viability of control, unlabeled cells was compared to that of NR-sgc8labeled cells. The dead cell percentage for unlabeled and labeled cells was $17( \pm 1) \%$ and $24( \pm 1) \%$, respectively, which supports the idea that the conjugate itself shows little or no toxicity to the cells.

We next tested cell death induced by laser irradiation after apt-NR labeling. To accomplish this, cells were incubated with aptamer-conjugated NRs and then exposed to a laser light of 808 $\mathrm{nm}$ at $600 \mathrm{~mW}$. Cell death was determined by using PI dye and monitored by flow cytometry. Figure 2 demonstrates that direct irradiation of the CEM cells alone had no effect on cell viability. The dead cell percentage remains the same after a 5 min light exposure $(600 \mathrm{~mW})$. The low light absorption by natural

(37) Nikoobakht, B.; El-Sayed, M. A. Chem. Mater. 2003, 15, 1957-1962. (38) Connor, E. E.; Mwamuka, J.; Gole, A.; Murphy, C. J.; Wyatt, M. D. Small 2005, 1, 325-327. 

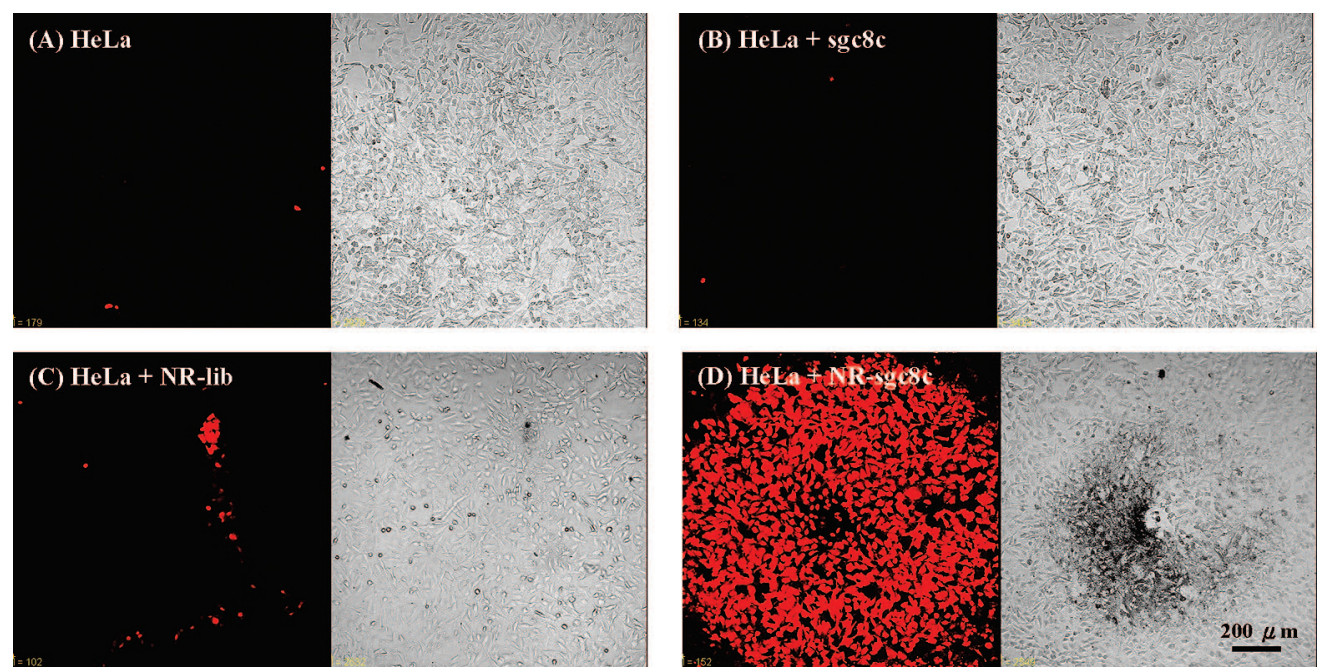

Figure 4. Microscopic images of (A) HeLa cells without NRs (A) and those labeled with sgc8c (50 nM) (B), NR-lib (0.25 nM) (C), and NR-sgc8c $(0.25 \mathrm{nM})(\mathrm{D})$. Cells are irradiated with NIR light $(808 \mathrm{~nm})$ at $600 \mathrm{~mW}$ for $10 \mathrm{~min}$. Dead cells are stained with PI dye and show red fluorescence. (Left) Fluorescence images of HeLa cells. (Right) Optical images of HeLa cells.

endogenous cytochromes of these cells accounts for their survival in the absence of NRs. ${ }^{39,40}$ On the contrary, cells which had been labeled with NR-sgc8c, and then irradiated, were killed with a percentage of $93( \pm 11) \%$, while no effect could be observed on the sgc $8 \mathrm{c}(50 \mathrm{nM})$-labeled CEM cells. These results are congruent with a mechanism whereby $\mathrm{Au}-\mathrm{Ag}$ NRs absorb laser light in the NIR range, convert it to heat, and then release the heat energy to the immediately surrounding medium, leading to the destruction of adjacent cells. ${ }^{41,42}$ The specific killing efficiency was investigated by incubating target cells with NR-conjugated random DNA (NR-lib) under experimental conditions identical to those for NR-sgc8c (Figure 2). The percentage of dead cells before and after illumination was $21( \pm 1) \%$ and $23( \pm 1) \%$, respectively. Furthermore, control (NB-4) cells were tested with the binding of NR-sgc8c on ice for $2 \mathrm{~h}$, followed by exposure to the laser at $600 \mathrm{~mW}$. The percentage of dead cells remained the same after light irradiation $(5 \pm 1 \%)$. These results indicate that our NR-conjugated aptamers show minimal nonspecific binding and are therefore highly promising for selective cell recognition and targeted cancer cell therapy.

We further demonstrate the selective cell targeting and photothermal capabilities of our aptamer-conjugated NRs in a cell mixture. CEM cells labeled with FITC-labeled anti-CD5 antibody showing strong green fluorescence around the cell membrane can be easily distinguished from NB-cells (Figure $\mathrm{S} 2$, Supporting Information). After incubation of this cell mixture with NR-sgc8c for $2 \mathrm{~h}$, only CEM cells were bound with NR$\operatorname{sgc} 8 \mathrm{c}$ and showed red fluorscence on their periphery. The appearance of little or no red fluorescence for NB-4 cells (cells without green fluorescence) further confirms the high specificity of our NR-aptamer conjugates toward cell targeting. After exposure to a laser light of $808 \mathrm{~nm}$ at $600 \mathrm{~mW}$ for $0-9 \mathrm{~min}$, cells were stained with PI dye and tested by flow cytometry (Figure 3). By using the dot plot of side scattering (SSC) versus FITC fluorescence, we can easily distinguish FITC-labeled anti-CD5

(39) Vladimirov, Y. A.; Osipov, A. N.; Klebanov, G. I. Biochemistry (Moscow) 2004, 69, 81-90.

(40) Zharov, V. P.; Mercer, K. E.; Galitovskaya, E. N.; Smeltzer, M. S. Biophys. J. 2006, 90, 619-627.

(41) Link, S.; El-Sayed, M. A. Int. Rev. Phys. Chem. 2000, 19, 409-453.

(42) Pissuwan, D.; Valenzuela, S. M.; Killingsworth, M. C.; Xu, X. D.; Cortie, M. B. J. Nanopart. Res. 2007, 9, 1109-1124. 4894.
CEM cells from NB-4 cells. Without light irradiation, the dead cell percentages of FITC-labeled anti-CD5 CEM and NB-4 cells were $24( \pm 1) \%$ and $4( \pm 1) \%$, respectively. By setting these two values to zero, Figure $3 \mathrm{~B}$ clearly demonstrates that the relative percentage of CEM dead cells grows faster in comparison to NB-4 cells as the exposure time increases. Specifically, after 9 min of irradiation, the relative dead cell percentage of CEM and NB-4 cells becomes $26( \pm 1) \%$ and $9( \pm 1) \%$, respectively. These results additionally support our aptamer-conjugated NRs as highly promising for selective cancer cell treatment.

It should be noted that the selective killing efficiency was somehow limited by the small sample volume $(10 \mu \mathrm{L})$ we used. NB-4 (control cells) may also be killed nonspecifically as a result of the increasing temperature of the whole suspension upon light exposure. However, since heat can dissipate easily in floating body fluids, we believe that this dual killing effect has no clinical significance. Confocal fluorescence imaging shows similar results (Figure S3, Supporting Information). After irradiation, $60( \pm 15) \%$ of the green cells (CEM cells) were dead and could be stained with PI dye, while only $12( \pm 2) \%$ of NB-4 cells (without FITC antibody labeling) were killed in the same cell mixture (Figure S3B, Supporting Information). The better killing selectivity, as calculated from confocal imaging, over that of flow cytometry is probably due to the higher sensitivity of confocal microscopy as well as the underestimation of dead cell population by flow cytometry when cells become fragmented upon severe damage.

For further treatment in solid tumor, we also demonstrate the therapeutic efficacy of our aptamer nanoconjugates toward adherent cell lines (Figure 4). NR-sgc8c can recognize their target protein receptors on the membrane surface of HeLa cells. These particles absorb light and convert it to heat, leading to cell death after exposure to the laser at $600 \mathrm{~mW}$ for $10 \mathrm{~min}$. Cell death is shown as a red spot in a circular region that matches the laser spot size. However, the cells outside the laser spot are viable, as indicated by their ability to expunge the PI dye. This result further confirms that these NR-conjugated aptamers are not themselves cytotoxic. At this energy, only cells bound with NR$\operatorname{sgc} 8 \mathrm{c}$ are damaged. No injuries to the cells are observed for either unlabeled or sgc8c-labeled HeLa cells. Little or no destruction of cells, which had been labeled with NR-conjugated random DNA (NR-lib), shows minimal nonspecific binding and further strengthens the point that these NR-aptamer conjugates 
are highly promising for selective cell targeting and photothermal therapy (Figure 4).

The efficiency of $\mathrm{Au}-\mathrm{Ag} \mathrm{NRs}$ as a photothermal therapeutic agent was also confirmed by monitoring the evolution of NRsgc8c-labeled HeLa cells during light exposure (Figure S4, Supporting Information). Cells can be easily destroyed in less than $10 \mathrm{~min}$ under light irradiation at $600 \mathrm{~mW}$. However, to determine the overall effect of laser light energy on surrounding tissue, it is also necessary to understand the spatial distribution of that energy. For our purposes, Gaussian distribution is assumed for the spatial distribution of laser energy. Therefore, the progress of cell death is shown to spread out from the right downward corner site of each figure, which is the central area of the laser source. In general, current literature assumes that the damage of adjacent cellular tissue by nanoparticle-assisted phototherapy may be caused by either (or both) of two effects. ${ }^{42}$ First, the localized increases of surrounding medium lead to perforation of adjacent cell membranes, protein denaturation, and heat stress. Second, explosive generation and cavitation of steam bubbles formed by overheating of the surrounding liquid layer around hot nanoparticles as well as the fragmentation of the nanoparticles will both produce mechanical and acoustic damage to the membranes. However, acousto-mechanical damage to the adjacent cell membranes usually occurs with exposure to light with higher pulse energy. In our case, we believe that the destructive effect was exerted by means of heat stress on the cells rather than by mechanical perforation of their membranes. Clearly, although the laser used here was adequate for in vitro testing, a more intense and localized source, such as a high energy pulse laser, would be required for in vivo studies.

\section{Conclusions}

In summary, we demonstrated the use of aptamer-conjugated nanostructures as an efficient and selective therapeutic agent for targeted cell recognition and photothermal destruction. Most nanomaterials require a relatively high power of laser irradiation. In contrast, the high absorption characteristic of our $\mathrm{Au}-$ Ag NRs requires only $8.5 \times 10^{4} \mathrm{~W} / \mathrm{m}^{2}$ laser exposure to induce $93( \pm 11) \%$ cell death of NR-aptamer-labeled cells. In addition, only about $50( \pm 1) \%$ of target (CEM) cells were damaged after laser irradiation, while $87( \pm 1) \%$ of control (NB-4) cells remained intact in a suspension cell mixture. Finally, our engineering combined the use of aptamers as recognition units, leading to selective binding of the NRs to the target cells. Thus, for future in vivo application, it is fully anticipated that the tumor tissue will be selectively destroyed at laser energies which will not harm the surrounding normal tissue. This is a direct result of the higher concentration of NRs selectively bound to the tumor tissue and their higher absorption characteristic. Overall, these results indicate that $\mathrm{Au}-\mathrm{Ag}$ NRs are effective and safe and thus promising candidates for use in phototherapeutic applications.

Acknowledgment. This work was supported by NIH, NCI, and NIGMS grants, by the State of Florida Center for NanoBiosensors, and by an ONR grant. Y.-F.H. acknowledges the support from the National Science Council (NSC095SAFI564625TMS) of Taiwan.

Supporting Information Available: Description of the materials, experimental details, and supplementary figures. This material is available free of charge via the Internet at http://pubs.acs.org.

LA801969C 